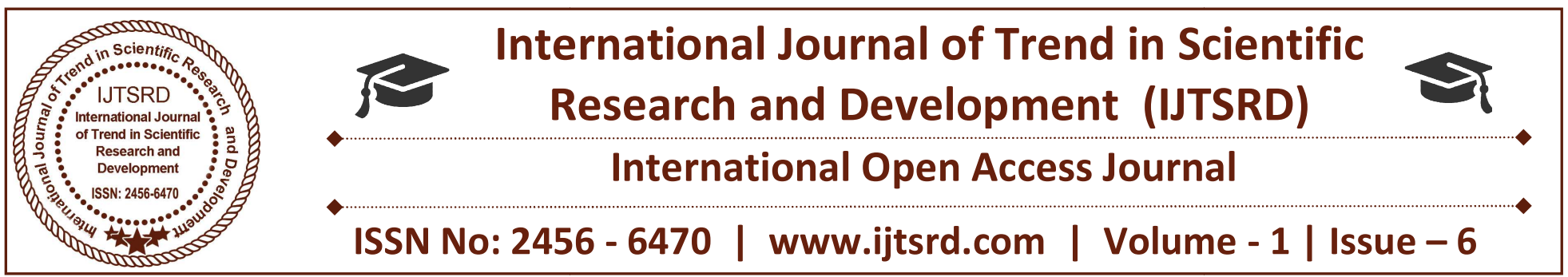

\title{
Development Perspective of Television Broadcast in Kazakhstan
}

\author{
Gainizhamal Abildina \\ Honored Worker of the Republic of Kazakhstan, \\ Professor at T. K. ZhurgenovKazNAA
}

\begin{abstract}
Mass media - media, namely television, radio, newspapers, magazines, are essentially the same providing a mass audience with social information - at the same time vary in the way it is delivered. The newspaper is a printed word, radio is speech and sound, television is an organic "triad": word, sound and image. Since the image has a similarity to the displayed object, and the conventional sign does not, then the natural verbal language is usually referred to as conditional sign systems, and the image to unconditional ones. Поскольку изображение обладает сходством с отображаемым объектом, а условный знак - нет, то естественный словесный язык принято относить к условным знаковым системам, а изображение - в безусловным.
\end{abstract}

Keywords: mass media, television, information, language, sound, image, technology

In the $21^{\text {st }}$ century, the tracking the emergence of new knowledge and their implementation became very important. Scientific knowledge and ability to apply them affect the level of economic and political stability, the quality of life, work, family income, health, etc. Increasing the educational level of the people promotes the development of high technologies, strengthens the aggregate power of the country and its international competitiveness.

Any television program in one form or another brings the viewer to culture. Even in the news reports, the appearance of the people being shown, their manner of communication, and the degree of literacy affect the viewer's attitudes. Television introduces viewers to the values of culture, completely transiting theatrical performance or a television movie. These forms, which belong to art, are outside of journalism and, consequently, beyond our consideration. At the same time, there is an important sign of professionalism in using figurative possibilities of the screen as a whole in TV journalism, as well as in the special programs with cultural and educational direction.

"We are moving towards a post-industrial world in which the triad "education-scienceinnovation" rules," the President of Kazakhstan said in his lecture at Nazarbayev University.

Enlightenment and educational television is one of the most effective tools that help a person to decide his destiny, mastering new knowledge. This knowledge gives a person the opportunity to live in a modern society and change it.

"In cultural and educational programs, one way or another, there is an element of moral teaching, didacticism. It is important to make it unobtrusive, delicate." [1.45].

The world experience of educational television, whose history began in 1953 in the United States, shows that both economically and politically powerful powers see the main factor of development in the educated population.

In his message “'Strategy Kazakhstan-2050”: a new political course of the state" The President of 
Kazakhstan determined the need for "Intensive introduction of innovative methods, solutions and tools into the domestic education system, including distance learning and online learning, accessible to all comers"[2].

The main priorities at this level are the dissemination of scientific and cultural information, assistance in training and the perception of new knowledge of various levels and types. The knowledge that educational television carries is always based on the importance of universal education, the ideas of serving the society. They not only teach the schoolchildren and students, but also other spectators; not only transfer scientific, but also public, moral and ethical knowledge. By connecting the school with the family and the public, continuing the educational process outside the school or university, educational television, we hope, will play an indispensable role in the life of society.

"The TV-image has redundancy, which makes it one of the most popular mass media. Today there is an exponential growth of sign systems, languages of the media in particular"[3]. "Sound Language" precedes all other symbolic systems of communication, while "written speech is poorer than oral" [4]. As a fast and dynamically developing country, Kazakhstan has embarked on the development of non-state television, through which many other countries go: from simply educational to cognitive to non-governmental television, which will offer different segments of the audience relevant content to their needs.

Conceptual tasks, the implementation of which is strategically important within the framework of television.

The fulfillment of the operational tasks facing television channels is called upon to ensure the continuous process of providing the air with a quality television product, targeted promotion of the programs among target audience.

The whole complex of broadcast programs must take on the task of spreading knowledge, including scientific ones, to perceive the beauty of culture and art, to transmit educational information, to carry out educational tasks, to conduct a constant dialogue with the viewer through news programs, talk shows, documentaries, entertainment programs, performances, movies, etc.
As for television, in our opinion, it should be based on four functions:

$>$ dissemination of scientific knowledge (educational),

$>$ propaganda of cultural heritage (pedagogic),

$>$-transmission of educational information (informational),

$>$ promotion of progressive views on the educational process (organizational).

Thus, educational television is one of the most important ways of disseminating and preserving the national culture and tradition and fulfilling an educational function.

The creation of a national educational television channel, in addition to the basic idea of enlightening the younger generation of Kazakhstanis, fulfills the task of creating a solid foundation for the implementation of the project of remote teacher training. Training using television requires less investment, while results are achieved quickly. Teacher training through distance education is an important factor in the development of teachers, especially in remote regions of our country.

On September 5, 2012, at the initiative of the Head of State Nursultan Nazarbayev, the first Kazakhstani educational channel "Bilim"was opened.

The mission of the first Kazakhstani educational channel was primarily to involve the viewer in the world of science and education, to show all the beauty and depth of Kazakh and world art and literature, to surprise, enlighten and expand the boundaries of knowledge and understanding of phenomena and processes; explain scientific and technological and historical processes using all available to date audiovisual tools and three-dimensional computer graphics.

"Television as a new form of introducing the people to art is a unique tool. However, this is not enough. Television creates its own artistic production, attracting to this work again the best of our playwrights, actors, composers". [5,139]

The work of creative groups reflects the orderly hierarchy of goals, which is aimed at fulfilling the main goal - achieving a high level of television viewing of the channel. The sequential decomposition of the main goal into tasks gives us an accurate 
strategic plan and tools for the development of Kazakhstani television channels.

The layout of programs on the channels has four main features:

$>$ First, different programsare broadcasted in accordance with the working and rest hour segments of our audience.

$>$ Secondly, in the evening the most popular programs, entertaining, television performances and screen versions of works of world literature are laid in the broadcasting grid in order to keep the maximum number of spectators in front of the screens.

$>$ Thirdly, new programs are constantly being created to attract and retain the attention of viewers.

$>$ Fourthly, fixing the memory of the past for the audience, the programs and films of the past are broadcasted.

The air and the whole TV channel program is designed for a wide audience of pupils, students; teachers of secondary schools, lyceums and universities, parents, as well as spectators of different ages and social status, interested in gaining access to the basics of knowledge.

For example, the audience of the channel "Bilim" coverfour sectors:

○ schoolchildren aged 10-17

o students aged 18-22

○ scientific and teaching staff

$\circ$ population interested in acquiring new knowledge, expanding their horizons.

It needs to be noted that only on the channels the audience saw the exclusive television production of the world famous company. However, only the closing of the Discovery channels in the cable networks in Kazakhstan (which should not have been done) allowed the creative groups of some channels to implement plans for the joint production of documentaries about the history, nature, development of Kazakhstan.

In addition, $\mathrm{TV}$ channels offer the best documentary products from Da Vinci Learning, National Geographic, CNN and others.

At one time, "Bilim" became the only television channel in the world that received the right to broadcast popular and world-famous TED lectures, where the great scientific minds of the present, wellknown public and political figures, the most successful entrepreneurs of the world take the stage.

The global trend in the development of modern television shows that TV viewers are increasingly interested in educational and learning programs, but the educational public television channel is difficult to deal with channels focused on entertainment content, movies and popular music. Commercial channels compete for ratings directly related to the amount of money received from advertising. Educational television is driven by the desire to attract the viewer with interesting and developing programs, cultivating human values and educating the individual. Educational television programs must withstand competition with commercial and entertainment TV broadcasting in Kazakhstan.

However, we always remember that there is nota country in the world that would dynamically develop, orienting itself on entering the world community, without having an obligatory element of educational television. Europe, America, Asia, and Australia - all countries that are oriented toward modern civilization have educational public broadcasting.

The purpose of cultural and educational television is to serve the community, appeal to every person as a citizen, spread knowledge, expand people's ideas about the world and other people, help people to know themselves.

Anyways, today television should give much more positive and cognitive emotions to satisfy the audience demand now. Fortunately, Kazakhstanis still have previous cultural achievements, such as theater, circus, and opera, galleries, which do not allow us to cultivate TV as the only available source. Therefore, to be morally protected by its influence,which is difficult to say about the younger generation, whose parents are not accessible on a material basis, leading their children to various recreational cultural institutions at a wrong time. The Internet also does not replace a living impression of a work of art or other aesthetic enjoyment, whether it be music, dance, artist's painting or sculpture.

The mass media, television in particular, not only promote cultural exchange in the field of art and culture, outstanding works of the human spirit and 
mind, it erases ethnic boundaries and in purely pragmatic spheres, such as life, lifestyle, etc. The socalled "mass culture" coming to us through global broadcasting (satellite television) contributes to the fact that a certain fashionable type of beauty, clothes, dominates in the world, national peculiarities are lost, and the national traditions are forgotten. Young people all over the world walk in the same clothes, sing popular songs and dance the same popular dances. And here, we must admit that Western samples dominate us today, which is greatly facilitated by the development of the television and film industry.

Today, the appearance and structure of television itself is irrevocably changing, and its influence on the masses is growing. Moreover, we must take into account that this influence has ceased to be clearly aimed as before, but acquires a veiled nature, more precise psychological motives. In addition, if we take into account that the system of organizing public leisure is not sufficiently developed, then it is possible to tell what a huge impact TV is getting. Moreover, much depends on the extent to which its main development directions will correspond to general human values, improve the communicative direction of its activities.

Television is gradually becoming deeper and more internally emancipated. The cruel conditions of our own way of developing market relations made all the bodies of the television, without exception; seek new ways of economic and creative survival. Advertising, the struggle for the viewer market, the emergence of healthy competition, as well as the differentiation of broadcasting, its semi-functionality, and the tasks of forming its own autonomous information space are the main trends in the development of information business in the country at the end of the nineteenth century.

As we know, television can reach out to the widest sections of the population, even those that remain outside the influence of other media. This ability of television is explained by the peculiarities of its physical nature, which determine the specificity of television as a means of creating and transmitting messages.

\section{LITERATURE}

1) G.Kuznetsov. Televizionnayajurnalistika (Television journalism). M., 2002

2) N. Nazarbayev. Strategy “Kazakhstan-2050.”, A.

3) E.Bagirov. Mesto TV v sisteme SMI ipropogandy (Place of TV in the system of mass media and propaganda). M.MSU., 1976

4) E.Bagirov. Ocherkitearii TV (Essays on the theory of TV). M., Iskusstvo., 1978

5) M. Ulyanov. Nash drug - televidenie (Our friend -television). M., Iskusstvo., 1978

6) G.Abildina. Iskusstvo TV: teoriyaitechnologiya (The Art of TV: Theory and Technology). A., 2012 